\title{
Desarraigo e ironía al filo de las nuevas historias: Últimos días coloniales en el Alto Perú (1896) de Gabriel René Moreno
}

\author{
Uprooting and irony on the edge of new stories: Gabriel René Moreno's \\ Últimos días coloniales en el Alto Perú (1896)
}

\author{
Sergio Mejía \\ smejia@uniandes.edu.co \\ Profesor asistente \\ Universidad de los Andes \\ Calle $18^{a}$, no 0-19 \\ 2501 - Bogotá \\ Colombia
}

\section{Resumen}

Este artículo es un comentario de Últimos días coloniales en el Alto Perú (1896-1901), del historiador boliviano Gabriel René Moreno (1836-1908) y su objetivo, inscribir el libro en la historia de la interpretación republicana americana en el siglo XIX. Aspiro a demostrar que su obra trascendió el paradigma historiográfico americano del siglo XIX - el de las historias republicanas monumentales - y que por su actitud ante el tema y ante la misma escritura de la historia, Moreno superó a su tiempo y abrió nuevos horizontes a la interpretación americana. Explico esta libertad intempestiva, adelantada a su tiempo, con la lectura detallada de la obra y con recurso a su biografía, marcada por el desarraigo patriótico.

\section{Palabras clave}

América Latina; Acontecimiento; Historicismo.

\begin{abstract}
This paper is a commentary on Últimos días coloniales en el Alto Perú (1896/1901), a work by the Bolivian historian Gabriel René Moreno (1836-1908). Its aim is to situate this historical text in the context of nineteenth-century Latin American historiography. I set out to show that this work transcended then prevalent historiographical paradigm - that of monumental republican histories - and that, due to his attitude toward both his subject matter (clearly forwarded in the book title) and historical writing in general, Moreno went ahead of his own time, thus opening new horizons to republican interpretations of Latin American history. I interpret the work's insightful and untimely freedom with by means of a close-reading of últimos días and with recourse to the author's biography, which was marked by patriotic distance.
\end{abstract}

\section{Keywords}

Latin America; Event; Historicism.

Enviado el: 15/1/2013

Aprobado el: 7/4/2013 
Sostengo en estas páginas que con la obra de Gabriel René Moreno (Santa Cruz de la Sierra, Bolivia, 1836 - Valparaíso, Chile, 1908) terminan un siglo y un modo de la interpretación americana. Su obra fue intempestiva, fuera de tiempo y sazón; su modo, la ironía; su método, la zapa erudita, con la que minó las certidumbres patrióticas de su siglo. Su libro Últimos días coloniales en el Alto Perú, fue obra adelantada a su tiempo (MORENO 1896). ${ }^{1}$ Por la época en que Bartolomé Mitre completaba su biografía de Manuel Belgrano, y con ella el decálogo gratificante, excesivo y serísimo del patriotismo argentino, y cuando Barros Arana aun no daba largada a sus 16 volúmenes sobre el broncíneo orden chileno, Moreno escribía un libro irónico y crítico en el que miraba a América con ojos nuevos.

Apunto a comprender su libro en la historia de la interpretación americana, a la que me he referido con la expresión historicismo americano (MEJÍA 2007; 2009). No hablo de la historia del concepto de América, ni de la búsqueda de ideas americanas a la manera de los americanistas, sino de la escritura sobre América que proliferó desde el siglo XVI y que a lo largo del siglo XIX sirvió para ordenar, desde Canadá hasta la Argentina, pasando por Haití y el Brasil, el patrimonio histórico de las nuevas repúblicas. En el anaquel decimonónico de la biblioteca americana, Últimos días ocupa el lugar finisecular y trascendental, en el sentido de camino al porvenir.

El colombiano Germán Colmenares sostuvo en 1987 que los historiadores americanos del siglo XIX suscribieron en sus obras convenciones historiográficas 156 opuestas a la cultura (COLMENARES 1987). ${ }^{2}$ Quiso decir que adoptaron convenciones europeas, con lo que omitieron observar de primera mano sus propias sociedades. Colmenares pierde de vista un hecho fundamental: esas convenciones historiográficas evolucionaron durante siglos, incluso milenios, en comunidades letradas; en ciudades-estado, imperios, cortes, iglesias y escuelas; y en diversos momentos y lugares muy anteriores a los desarrollos europeos modernos. Con la consolidación del mundo atlántico, las convenciones tradicionales siguieron su evolución tanto en Europa como en América. No eran otras que la prosa narrativa cronológica; el comentario moral de los hechos; la invocación de alguna forma de justicia; y la dedicatoria a un poder de este mundo.

El argumento de Colmenares, si bien lúcido, padece de una enfermedad cultural común en las culturas escritas americanas: la inseguridad con respecto a nuestro lugar en el mundo. Ello explica las repetidas salidas en falso en la búsqueda de referentes culturales. Colmenares dedica las últimas páginas de Convenciones al libro de Moreno. A diferencia de sus comentarios sobre las historias de José Manuel Restrepo, Bartolomé Mitre y Diego Barros Arana, por ejemplo - en cada una de las cuales expone una "convención contra la cultura" -, de Últimos días solo pondera el lenguaje rico y matizado. No percibe diferencias

\footnotetext{
${ }^{1}$ Moreno reunió y trascribió documentos inéditos que publicó en un segundo volumen (MORENO 1901). Las cuatro quintas partes del libro fueron publicadas por entregas entre 1876 y 1898 en los Anales de la Universidad de Chile, la Revista Chilena y la Revista de Artes y Letras, las tres de Santiago de Chile.

2 En este estudio Colmenares solo tuvo en cuenta a una selección de historias suramericanas, con exclusión de haitianas, otras caribeñas, brasileñas, centroamericanas, mexicanas y norteamericanas.
} 
entre Últimos días y las otras historias que comenta. De hacerlo, acaso habría cerrado su ensayo con una contradicción de términos.

No está de más una nota de aviso al lector. Moreno fue un gran escritor, y los grandes escritores deben ser comentados con cierta humildad, pero sin reverencia. El comentador haría un esfuerzo improductivo si acallara su voz. Así pues, ilustro con riqueza y sistemáticamente la prosa histórica de Moreno, verdadero tema de este artículo: una prosa que fue resultado de su particular comprensión de la escritura histórica y de una sensibilidad entonces nueva ante la devoción y el deber patrióticos. Le pido al lector que acepte la citación sistemática (ordenada analíticamente por mí), pues es la prosa de Últimos días la que ubico en la evolución histórica del historicismo americano. Es decir, en la larga y plural tradición de interpretación y comentario sobre las repúblicas en América.

Este artículo es un avance del penúltimo capítulo de un libro en preparación sobre la historia, entre las últimas décadas del siglo XVIII y las primeras del $X X$, de lo que he llamado el historicismo americano. El capítulo sobre Moreno vendrá precedido por un estudio sobre la Historia jeneral de Chile (1884-1902) de Diego Barros Arana y, en particular, sobre la actitud melancólica del autor al cabo de un trabajo de veinte años, pues Barros Arana alcanzó a comprender que la suya sería la última historia monumental americana escrita para contener toda la historia relevante de una república. El capítulo subsecuente y final será un estudio sobre la figuración de la república entre los poetas modernistas, que ya no será histórica, monumental y adusta, sino breve, crítica y pronunciada desde las alturas del Parnaso de la poesía.

\section{Lo que se ha escrito sobre Moreno y su obra}

En 1988 José Luis Roca constataba la existencia de morenistas -los que han estudiado a Moreno-, y morenianos -los que se vieron influenciados por él - (ROCA 1988), a los que deben agregarse las "morenadas", volúmenes enteros dedicados a comentar su vida y obra, todos útiles, todos algo redundantes. ${ }^{3}$ También en 1988, Josep Barnadas revisó los estudios acumulados sobre Moreno y los dividió en tres épocas: a los publicados entre 1907 y 1933 los llamó impresionistas; entre 1933 y 1954, revisionistas; y entre 1954 y 1985, eruditos (BARNADAS 1988). Dio largada a los impresionistas Jaime Mendoza con el recuerdo de la visita que hizo a Moreno en Santiago en 1907 (MENDOZA 1937). Siguieron diccionaristas de la literatura nacional, quienes reservaron alguna entrada para Moreno. ${ }^{4}$ Comentarios revisionistas abundaron luego de que en las legislaturas de 1933 y 1934 se debatió la edición de sus obras a costas del erario público, compuerta a opositores y defensores. En 1936 Humberto Vásquez Machicado asentó carrera de morenista con una justificación de la sociología de Moreno (su explicación racial de la historia boliviana), y en 1954 publicó un estudio general introductorio de los Estudios de Literatura Boliviana, compilación de sueltos de

\footnotetext{
3 Otras morenadas útiles, son las siguientes: MENDOZA 1951; SANABRIA FERNÁNDEZ 1961; SILES GUEVARA 1979; OVANDO SANZ 1996.

4 Barnadas omite el "impresionista" estudio de Emilio Finot, con anotaciones biográficas y el comentario a pincel ligero de veinte de sus publicaciones (FINOT 1910).
} 
Moreno (VÁSQUEZ MACHICADO 1955). Revisionista fue Carlos Medinacelli, quien reconoció la calidad de la pluma del cruceño, pero insistió en ver en él a un escritor español, dolorida encrucijada de los estudios bolivianos, todavía inseguros sobre qué es Bolivia y qué letras son suyas (MEDINACELLI 1946).

En cuanto a la época erudita (1954-1988), de 1971 data su biografía por Ramiro Condarco (CONDARCO MORALES 1971), de 1967 la bibliografía por Juan Siles Guevara (SILES GUEVARA 1967) y desde 1962 se acumulan estudios por extranjeros como Charles Arnade, Gertrude Yeager y Marie Demelas. En 1988 se abre un periodo nuevo, que llamo de morenadas. Al compendio de Barnadas se suman los de Guillermo Ovando Sanz y José Luis Roca, el primero con la mejor bibliografía de Moreno disponible (OVANDO SANZ 1996, p. 177-386). Tres morenadas colectivas resultan de gran utilidad: la primera, con ocasión del sesquicentenario de su natalicio, reúne estudios sobre el hombre (VARIOS AUTORES 1986). La segunda, en el centenario de la publicación de Últimos días, es una selección de comentarios breves sobre la obra (VARIOS AUTORES 1996). La tercera, Gabriel René Moreno íntimo, editado por José Luis Roca, con cartas y testimonios reveladores sobre el hombre (ROCA 1986). Desde 2005 Bolivia vive el Pachakuti, presidido por Evo Morales. Está por verse qué apropiación se haga en los años por venir de un escritor camba e irónico del siglo XIX. El ambiente no está para morenadas, y sus libros hoy sirven como obras de consulta (OVANDO SANZ 1996): Últimos días coloniales en el Alto Perú, entre los estudiosos de la independencia (ROCA 1998); el Catálogo de Mojos y Chiquitos, entre los

158 del oriente boliviano. La Biblioteca Boliviana y la Biblioteca Peruana, son obras fundamentales de referencia, índices elaborados por Arze Aguirre.

Mi contribución apunta a incluir la obra del historiador y erudito en un estudio general de la historiografía republicana americana del siglo XIX. En América aun no contamos con una reflexión general sobre la historiografía republicana aparte del mencionado ensayo de Germán Colmenares. Si bien es crítico, sugerente y por momentos profundo, Convenciones contra la cultura no alcanza a sugerir la extensión y el ámbito propiamente americanos de la historiografía republicana del siglo XIX. No fueron únicamente los nuevos regímenes hispanoamericanos los que demandaron con urgencia la reflexión histórica, sino también el de los Estados Unidos, el haitiano, el brasileño (aunque su forma fue monárquica, era su emancipación la que demandaba la narración y la justificación históricas), e incluso el canadiense, aunque sus provincias permaneciesen leales al rey. Colmenares tampoco logra comentar la evolución histórica del género mayor en la interpretación republicana en el siglo XIX - el de las historias monumentales - y su libro es una suma de ensayos monográficos sobre historias sudamericanas. Cierto que extrae de su estudio una conclusión general: esas historias funcionaron como "convenciones contra la cultura", pues simplificaron la complejidad social de las nuevas repúblicas en aras de producir discursos "nacionales". En justicia, es necesario decir que Colmenares intuyó la importancia de estas historias monumentales y llamó a su estudio, que él mismo comenzó de una manera amplia y ecuménica. 
Antes de Colmenares teníamos inventarios y periodizaciones genéricas, y luego de él hemos visto progresar los estudios "historiográficos" en todos los países, en unos más que en otros. Por lo general se ha progresado hasta monografías críticas sobre historiadores e historias, y en el caso de unos pocos países reflexiones sobre periodos, "escuelas" y épocas historiográficas. Igual ha sucedido con los comentadores norteamericanos y sudamericanos de sus propias historiografías republicanas. Pero aun nos hace falta una historia de las historias americanas del siglo XIX, que deberá dar lugar a la historia de la reflexión sobre las repúblicas americanas. América no inventó la república, pero sí se la apropió, y hecho esto las élites letradas de las nuevas repúblicas se obligaron a la reflexión continuada sobre ella, sus virtudes, sus vicios, sus dificultades y sus logros. El núcleo fuerte de la biblioteca americana en el siglo XIX (con extensión hasta el XVIII en los Estados Unidos y hasta el XX en el Caribe) es su anaquel de historias monumentales republicanas. No hemos tenido una expresión o concepto que las denote y permita disponerlas para su estudio histórico con amplitud y de manera orgánica. Para ello he propuesto la noción de historicismo americano, que permite construir un campo de estudio en el que caben las historias republicanas escritas en los cuatro idiomas coloniales americanos y que hace posible la comprensión de su evolución histórica, su lugar central de referencia en las culturas escritas de la región y su análisis por encima de la limitada perspectiva nacional. De esta manera se puede comprender, por ejemplo, el libro crítico, breve y acotado en su tema que fue Últimos días coloniales en el Alto Perú como una evolución intelectual, una nueva solución, más allá de la monumental Historia jeneral de Chile de Diego Barros Arana, y de sus hermanas en el paradigma de las historias monumentales y canónicas. Más aun, se puede comprender a últimos días en el contexto cultural más amplio de una nueva sensibilidad, enemiga de la devoción patriótica, de la narración épica y del ánimo de exhaustividad patria. Una sensibilidad modernista. Es lo que ilustro y sugiero en este artículo.

Procedo a explicar la estructura argumentativa de últimos días con el fin de inventariar los rasgos que la diferencian de historias precedentes y contemporáneas. En la segunda parte correlaciono la novedad de la obra con la libertad, la autonomía y el desarraigo patriótico que fueron la marca de la vida de su autor. En la conclusión, sugiero el lugar que Últimos días ocupa en la evolución del historicismo americano; es decir, de la historia de la reflexión republicana en América.

\section{Ironía intempestiva en Últimos días coloniales en el Alto Perú}

La profesión de Moreno fue la de crítico y su modo, la ironía. Antepuso en su evolución como escritor el comentario de lo ajeno a la creación de lo propio, y llevó sus comentarios hasta la risa moral, la ironía. Pulió su pluma comentando poetas, luego historiadores, más tarde impresos y en la madurez manuscritos. Últimos días coloniales en el Alto Perú es una serie de comentarios 
de manuscritos, elaborados en una historia. Sentenciados los poetas, ${ }^{5}$ pasó al comentario de historias con el libro de Manuel José Cortés, de 1861 (MORENO 1861. t. V, p. 219-231 y 385-401). ${ }^{6}$ Picado de erudición, se dedicó a la colección de impresos, y a comentarlos. De ahí su Biblioteca Boliviana y su Biblioteca Peruana. De ahí también sus Últimos días coloniales en el Alto Perú, comentario de sus manuscritos de Chuquisaca.

Una pregunta preside sobre el libro: ¿cómo surgió, y cuándo exactamente, en la leguleya y remota Chuquisaca de los últimos años coloniales, el pensamiento exorbitante de la revolución? Moreno no se dijo "voy a escribir la historia de Bolivia", como, en sus países se lo propusieron Mitre o Varnhagen. Si ellos narraron siglos y murieron convencidos de haber escrito las historias generales de sus repúblicas o las historias canónicas de sus revoluciones, Moreno, cubrió en Últimos días cuatro años, que consideró bastantes para establecer demostraciones según sus exigentes criterios sobre la historia.

Practicó el establecimiento documental, la lectura densa y la conclusión irónica. Cabe llamar la atención sobre dos facetas de la ironía, ambas presentes en la prosa de Moreno. Una es la ironía pionera, que anuncia el resquebrajamiento de antiguas certidumbres, propia de críticos sin poder. La otra es moderna tardía, propia de quienes ya gozan de poder. La primera ha sido estudiada con iluminación respecto al Siglo de Oro por Bruce Wardropper en un artículo clásico sobre los orígenes de la novela y los precedentes historiográficos de El Quijote (WARDROPPER 1965). La segunda, por Hayden White a propósito de 160 artistas e historiadores de finales del siglo XIX, orgullosos en el pináculo de su siglo y cercanos al abismo por el que se despeñarán las últimas certidumbres (WHITE 1973). Wardropper recuerda el afán de Cervantes por presentar su historia del Quijote como verídica, tomada de documentos auténticos por el historiador Cide Hamete Benengeli, y llama la atención sobre la fiebre de falsas historias publicadas en la España de entonces. Entre historia y ficción, explica Wardropper la naturaleza de la novela:

Cervantes es consciente de la aporía de la historia y comprende que debe manejar su pretensión de verdad y exactitud con grandes dosis de ironía [...] Los hombres, no escogemos entre el bien y el mal, como lo exige el moralista, sino entre mayores y menores bienes y entre mayores y menores males [...] Todo en la condición humana es un asunto de matices y El Quijote es, entre otras muchas cosas, una tremenda protesta contra el dogmatismo moral imperante en la España de la Contrarreforma (WARDROPPER 1965, p. 5-10).

Moreno miró con sonrisa cervantina a su Chuquisaca de los últimos años coloniales y supo ver los grises de la condición humana. Otra faceta de la ironía

\footnotetext{
${ }^{5}$ La primera publicación de Moreno vio la luz en Sucre en 1856, cuando tenía veinte años, en el periódico La Nueva Era: se trató de un comentario a la biografía de Antonio José de Sucre que ese mismo año publicó el neogranadino Manuel Ancízar. Publicó comentarios sobre la poetisa María Josefa Mujía, Daniel Calvo, Manuel José Tovar, Ricardo Bustamante, Mariano Ramallo, Néstor Galindo y de su amigo neogranadino Arcesio Escobar, traductor de Byron.

6 Moreno saluda este primer intento de historia de Bolivia, luego de las memorias sueltas de los protagonistas de la independencia; se opone a la sentencia de Cortés, "los pueblos esclavos no tienen historia"; y llama al estudio de la historia colonial. Existe reedición de este comentario en: MORENO 1955-1956, vol. 2, p. 177-216.
} 
es la que mira hacia el pasado. La de los modernos consumados, convencidos de la superioridad de su tiempo sobre tiempos pasados. Hayden White la estudió en Jakob Burckhardt, el suizo finisecular tan enamorado del Renacimiento italiano como convencido de la desencantada superioridad de su propio tiempo de trenes y filosofía positiva, cumbre gris desde la que observó a sus coloridos condotieros de coraza de lata y sus terribles proyectos de dominio comarcano en la Italia del Cinquecento. Moreno comprendió así a su arzobispo Moxó, a sus detestados doctores silogistas de Chuquisaca y hurgó en los entresijos de la cultura colonial.

\section{Estructura y función en Últimos días coloniales en el Alto Perú}

Concebido como un estudio de las causas de las revoluciones de Chuquisaca y de La Paz, Últimos días se interrumpe en noviembre de 1808. Este fue su primer atentado contra el atavismo de las historias monumentales. Moreno comprendió que los libros presentados por sus contemporáneos como historias completas de sus repúblicas eran ficciones. Últimos días fue, en cambio, pesquisa ceñida a documentos sobre un tema particular y restringido. Por otra parte, reflexión sobre una inquietud general ante la historia republicana de Bolivia. Fue su empeño comprender

[...] acontecimientos [que] se agruparon para sucederse con una inmediación que les dio el viso de simultáneos, se verificaron en consorcio de circunstancias lejanas o externas singularmente extraordinarias, y trajeron consigo en el Alto Perú mudanzas tan vastas, radicales y duraderas, que, si por causas notorias no fueron únicas ni exclusivas en aquesta colonia de América, fueron tales como los veinte y cinco mil habitantes de La Plata jamás las pudieron entonces imaginarse ni soñar (MORENO 1896, p. 4).

En cuanto a la mayor inquietud de Moreno, ella se lee en las palabras que cierran su libro:

Ha sido de este modo cómo, frecuentando desde un principio la escuela pública del disimulo y las simulaciones, un pueblo sano i varonil haya acabado por amar la adulación sistemática de sus políticos i sus escritores, i por aborrecer a quien quiera que le diga la verdad sobre sus faltas ante los peligros de muerte que le rodean. Que rodean esa existencia cuyo prístino oriente singular estábamos arriba señalando (MORENO 1896, p. 472).

Como las mejores historias, últimos días es un libro a dos niveles: una susceptible de demostración con documentos y pruebas, y que debe restringirse a un periodo breve y una pregunta clara. $Y$ otro tema mayor, de impronta en la cultura y la política, sobre el que concluye: en Charcas existió una sociedad educada y floreciente, pero los caudillos de Bolivia la han sometido a la vergüenza y al miedo. Moreno previó tres partes que tituló "Arzobispo nuevo", "Rei nuevo" y "Presidente nuevo", de las que escribió solo las primeras dos. En ellas despliega las interacciones de cinco grupos de personajes de la Chuquisaca colonial, "cuádruple corte eclesiástica, forense, literaria y social" (MORENO 1896, p. 4). Del gremio eclesiástico toma al arzobispo Benito María Moxó y Francolí; de la Audiencia, a su presidente, Ramón García León de Pizarro; a sus primeros contendores, los 
oidores; a los doctores de Chuquisaca, criollos "doscaras". Y suma un quinto malo, el diputado de la Junta de Sevilla, José Manuel de Goyeneche, quien sirve de vínculo con la política europea en la coyuntura de 1808. Moreno describe en diez pinceladas la ciudad de La Plata o Chuquisaca, "corte encerradísima" y pone en escena a Moxó (MORENO 1896, p. 11). Con su llegada y saludos, explica Moreno, la ciudad desató su lengua en clave nueva y fluida:

Desde la llegada del Arzobispo se dio allá en la flor de hablar entre estudiantes i letrados contra el silogismo, i que cuando alguno se descuidaba argumentando en la antigua forma, 'no se enrede, amigo, en esas vejeces (le gritaban), i razone de corrido como el señor Arzobispo' (MORENO 1896, p. 44).

Luego entra el presidente septuagenario, Ramón García León de Pizarro, "hombre manso y de trato llano", "escaso de luces, apacible en la modestia i sensato", otro entrañable de Moreno:

Moxó conoció en una ojeada que Pizarro era un septuagenario timorato, mui injenuo i bueno de carácter, de intención recta i limitado entendimiento, dócil al consejo i susceptible de ser dirijido. Era, por lo demás, un amigo útil, por cuanto ejercía el real vice-patronato en todo el Alto Perú (MORENO 1896, p. 126).

Introduce Moreno a la Audiencia de Charcas durante el régimen de intendencias, lo que le quitó sus principales facultades y la redujo "al carácter de corte de alzadas o tribunal supremo de justicia":

La prepotencia del rejio tribunal de Charcas durante más de dos siglos es un hecho histórico, rico en abusos i arbitrariedades de toda especie... Desde su retiro, o por mejor decir jubilación política i administrativa, el rejio tribunal lidiaba por ser, si cuando más no fuese en apariencias, lo que ya no era. Hubiérase dicho que había perdido la apostura severa i desenvuelta de la virilidad, i que mostraba su decrepitud entre contorsiones de altivez e impaciencia (MORENO 1896, p. 127-128).

Para introducir a los doctores de Chuquisaca, Moreno ha puesto a sus lectores en antecedentes sobre vocabularios y caramillos:

Llamábase entre los criollos vocabulario al cuentista, al parecer simplemente indiscreto, que no callaba lo que debiera i sí más bien revelaba lo que supo, o malició o atisbó... Malquistar el barrio, dividir las familias, promover, si fuera posible, algunos alborotos, eran, por aquel entonces, tarea poca injeniosa o medianamente burda i hasta trivial en ciertos pueblos i aldeas... El caramillo era un chismógrafo de aptitudes aventajadas para sembrar con mano invisible la cizaña de calidad fina i trascendente, i para cultivarla a oscuras con paciencia entre individuos destinados a llevarse en intimidad o en armonía (MORENO 1896, p. 121-122).

El primer caramillo en la escena de los Últimos días es el asesor del virrey, Pedro Vicente Cañete, que aunque paraguayo no se quedaba a la zaga de los mejores de Charcas: 
Por agosto de 1804 había venido a residir en Chuquisaca, con el carácter de asesor interino de la presidencia, un letrado que a la suma de conocimientos propios de un doctor in utroque, juntaba una destreza poco común para manejar con talento la lengua i la pluma (MORENO 1896 , p. 135-136).

Con las noticias de Bayona, se supo en Charcas de la "formación en Sevilla de una junta de gobierno titulada suprema i soberana de España e Indias, i el arribo a Buenos Aires de un representante suyo en estos virreinatos, José Manuel de Goyeneche". Luego de su paso disociador por Montevideo, y Buenos Aires, en noviembre de 1808 Ilegaba Goyeneche a Chuquisaca:

Ignoraban los ministros que el ajente de la junta sevillana por Fernando VII, había tenido a la vez conveniencias con Murat para venir en servicio de José Bonaparte a estas provincias. Ignoraban que traía pliegos seductivos de Doña Carlota del Brasil, infanta de España; pliegos mandados recabar por él secretamente a Río de Janeiro, infanta que pretendía suplantar a su hermano en estos dominios (MORENO 1896, p. 254).

Un sexto "personaje" reúne en colectivo a los anteriores y a sus circunstantes:

Se llamaba Asistencia. Formábalo el concurso resultante de hallarse congregados aparatosamente, es decir, en traje de ceremonia i en orden jerárquico, los individuos de las diversas secciones del servicio público i de las instituciones civiles i religiosas del país.... De repente todo el mundo se detiene en la calle, se descubre, se inclina: isilencio!, pasa la Asistencia (MORENO 1896, p. 257).

Moreno procede a desentrañar la madeja de actos y motivos. Empieza con Moxó, su bien amado y blanco mayor de su ironía. De "rostro casi femenino por la blancura imberbe de su tez, la suavidad de sus perfiles, la gracias de sus labios breves y rojos, el abultamiento terso de sus carrillos y la negra cabellera echada en bucles tras la oreja", saca del todos los colores de su paleta (MORENO 1896, p. 37-38).7 Sobre su llegada al "desmantelado palacio de los arzobispos", cascarón legado por el frugal San Alberto, comenta Moreno que si el rey Yugurta reconvino a los romanos con aquella sentencia, "iQué frías están vuestras estufas!", Moxó, por su parte, increpó al mayordomo con un no menos sonoro "iTodo esto no sirve para nada!" Y recabó de las provincias "vajilla de Potosí, petates de Mojos, vaqueta cochabambina, tejidos finísimos de chinchilla y vicuña, bujías en cera colorida de Chiquitos, alfombras de Clisa, ramilletes de plumas tropicales de Santa Cruz, cazoleta de las monjas carmelitas de la ciudad".

En cuanto al presidente Pizarro, su buena índole se agriará en querellas de preminencia con los oidores. El caramillo Cañete le dirá que abusan de su buena índole. "Eran brasas que echaron Ilamas dentro del edificio colonial [...] Lo cierto es que aquella lava, con todo de ser materia nimia i pueril, había dejado carcomidos i desintegrados los corazones, con ancha cavida para zañas i desquites 
revolvedores" (MORENO 1896, p. 144-145). Cierra la obertura: "Así se ve que una conmoción local i casi imprevista tenía raíces i tuvo ramificaciones dignas de la historia." Dignas, pero no por heroicas, sino por ruidosas. Llegan las infaustas noticias de Aranjuez y poco después las nefastas de Bayona, inverosímiles: el rey y el delfín abdicando, Napoleón artífice. Los oidores propusieron "callar y no innovar", pero, como dijo Cañete, era más fácil parar las aguas del Pilcomayo con empalizadas. Los oidores percibieron la tramoya de Goyeneche, solo para caer en la trampa de los doctores, y no esperaron la locuacidad del arzobispo:

Con patética elocuencia acertaba a expresar sentimientos patrióticos, no siempre oportunos de expresarse en aquellos momentos entre los vasallos de la colonia. Porque es lo cierto que cuando él entendía estar sirviendo con esta parla los intereses de la metrópoli, sembraba por otra la consternación con el espectáculo de las ruinas de España y pérdida de sus colonias, y provocaba con esto cavilaciones y quién sabe qué otras cosas en el espíritu de los oyentes (MORENO 1896, p. 166).

Moxó ordenó una colecta patriótica en las provincias altas. Los oidores vieron en ello un desacato contra su política de callar y no innovar. Moreno concluye que fue entonces cuando "penetró claramente en el intelecto de la plebe de Chuquisaca la idea cívica, por no darle otro nombre, sobre la existencia de ciertos motivos que debían unir en comunidad jeneral esta provincia con las demás del Alto Perú" (MORENO 1896, p. 233). Explica Moreno que los doctores criollos observaban la madeja de la crisis mientras hacían aspavientos 164 de lealtad a Fernando VII. Entonces entro Goyeneche en la ciudad, y cuando presentó sus pliegos el oidor regente, Antonio Boeto, objetó la legitimidad del "gobierno provincial tumultuario que los había espedido" (MORENO 1896, p. 450). Goyeneche increpó que "andarse enredando en leyes" era rayano en infidencia, a lo cual el regente se disparó en protestas a la voz de "iYo traidor, yo traidor!" Goyeneche aclaró que tenía facultad de hacer presos y requirió la guardia. Intervino el arzobispo para restituir la calma y entonces Goyeneche entregó las cartas de Carlota Joaquina para Pizarro y Moxó. Con esta explosiva reunión Moreno cierra su libro. Quedan pendientes las intrigas de los doctores criollos y los movimientos populares de mayo en Chuquisaca y de julio en La Paz. Si bien no las narra, Moreno dedica a las intrigas de los doctores "doscaras" los comentarios finales del libro:

Los instigadores de la raza no necesitarán de más para sus planes, tan solapados como los de Goyeneche [...] Sub fallacia regina, quis non fallitur et fallit? Engañar i ser engañado: he ahí el medio social dónde i cómo deben llevarse a cabo las más grandes cosas en el reino del engaño [...] Falacia así en el cimiento como en el coronamiento del edificio de la independencia (MORENO 1896, p. 471-472).

Si en 1809 hizo efecto el grito doctoral "Nos quieren vender al Portugal", en 1824, serán criollos de la misma laya quienes se plegarán al invasor. En el imperio de la mentira, ¿quién no es engañado y engaña? Doctores caramillos retornarán en 1824 para enquistarse en la historia de Bolivia, pues fue... 
[...] una lisonja pusilánime de los "doscaras" [la que] hará que al nuevo estado se den el nombre i la paternidad ¿de quién? Del que nada especial por dicho Estado había hecho jamás, que antes al contrario oponiéndose estaba a su existencia aparte, i que dejó deforme esta soberanía, vacilante, combatida desde sus primeros pasos, por no haber pensado él sino en tenerla uncida al carro de su dictadura en el Perú (MORENO 1896, p. 472).

Se refiere a Bolívar. Fue así como "frecuentando desde un principio la escuela pública del disimulo y las simulaciones, un pueblo sano i varonil haya acabado por amar la adulación sistemática de sus políticos i sus escritores, i por aborrecer a quien quiera que le diga la verdad sobre sus faltas ante los peligros de muerte que le rodean" (MORENO 1896, p. 472). ¿Cómo explicar tanta habilidad entre los doctores? Con ironía cervantina, Moreno se finge sorprendido de que en el rutinario estudio que los criollos hacían en la Suma Teológica (y política) de Santo Tomás alguno en efecto la entendiera, cosa notable si se tiene en cuenta que aun no disponían de "sus dos más luminosos comentadores: la revolución francesa i la democracia norteamericana" (MORENO 1896, p. 261). ¿Cómo se explica que Charcas se hubiera convertido en un tinglado de caudillos? Moreno les pinta la cara a los hombres de la independencia. ¿Cómo más podría ser, si fue entonces cuando su mal carácter sacudió la rienda colonial y tomó la dirigencia? "Momento jeneral será la pérdida de España; momento para todas las osadías, todas las impunidades, todos los atentados, todos los ideales de la ambición" (MORENO 1896, p. 472-473). Es decir, miserias humanas en lugar de héroes y modelos.

\section{Desarraigo, lucidez y libertad - Vida y obra de Gabriel René Moreno}

No sostengo que Moreno nos haya dado la mejor explicación de la revolución boliviana. La historiografía y la interpretación americanas han avanzado de maneras que Moreno no pudo imaginar. Sus explicaciones siguen siendo ad hominem, pues ignora el hecho social. Medio siglo correrá hasta que la interpretación americana se beneficie del análisis social moderno y, antes que nuevos historiadores, serán poetas modernistas quienes tomarán el relevo. El método de Moreno no es el nuestro, mas sus resultados ya son útiles. Su obra no es edificante, sino demoledora; su prosa no enaltece, denuncia; su tono no acaricia, golpea; sus ideas no halagan, ponen en alerta. Otro tanto harán los poetas modernistas que sucedieron a los historiadores republicanos en la historia de la interpretación americana. ¿Cómo rompió Moreno el cascarón de precauciones que protegía el blando retoño republicano contra interpretaciones duras, contra el atentado de la ironía?

Para empezar, Moreno fue hijo legítimo de hija natural. ${ }^{8}$ Su propio estatus no sufrió menoscabo por ello, pues también fue hijo de magistrado de la Corte Suprema de Justicia, de hombre a quien "no le causaron jamás, ni en la epidermis, el más leve rasguño las gacetas" (PRÓLOGO 1886, p. IV). Con 
su padre correspondió desde Chile, y sintió mucho no verlo más, pues murió antes de su primer retorno a casa. A su madre, Sinforosa del Rivero, la vio en Santa Cruz luego de quince años de ausencia. A los quince años dejó Santa Cruz, la patria que más quiso, y a los veinte su país, sobre el que escribió hasta su muerte. Su extranjería se convirtió en exilio cuando quiso servir a su país de la peor manera, como agente diplomático durante la Guerra del Pacífico. Moreno fue portador de la propuesta chilena al presidente Hilarión Daza, en que se ofrecía a Bolivia cambiar de bando. Saltó el escándalo cuando Daza hizo públicas las llamadas "bases chilenas", y Moreno fue acusado de traición. Tenía cuarenta y tres años. ${ }^{9}$ Su intervención diplomática debió figurársele, con el tiempo, similar a los desbarres del arzobispo Moxó: picado de diplomático, salió con el rabo entre las patas. Hasta su muerte, Moreno vivió al margen de cargos, obediencias, aspiraciones y honores, libre de negociaciones patrióticas. Testigo del arrebatado nacionalismo chileno, ajeno a la carrera de honores y cargos e ignorado en Bolivia, escribió su obra mientras cuidaba los libros de los bachilleres de Chile.

La bostoniana Mercy Otis Warren, historiadora de la revolución norteamericana, fue hija, esposa y anfitriona de los principales patriotas de Boston: James Otis, James Warren y John Adams. El colombiano José Manuel Restrepo fue secretario del dictador antioqueño Del Corral, luego constituyente, después ministro de Colombia y entonces historiador. El haitiano Thomas Madiou fue secretario personal de Inginac; ministro de Estado de Boyer; rector del 166 Lycée National d'Haiti; director del periódico oficial del régimen de Soulouque, Le Moniteur; ministro de educación en el régimen de Geffrard desde 1866. Gustavo Adolpho Varnhagen fue cortesano de Dom Pedro II, miembro del Instituto Histórico Geográphico Brasileiro e investido Vizconde de Porto Seguro en el Imperio. En fin, el argentino Bartolomé Mitre fue presidente, el ecuatoriano Federico González Suárez arzobispo y Barros Arana perito de límites, rector de la universidad y eminencia gris de sucesivos regímenes. Moreno fue, como él mismo decía, carga-papeles.

Fue nombrado bibliotecario interino de la Biblioteca del Instituto Nacional de Chile en 1868, luego de la renuncia del titular (Mss. GRM 146, F.1). Interinos fueron sus nombramientos como profesor de literatura en el Instituto Nacional en julio de 1887 y en enero de 1888 (Mss. GRM 146, F.3). En febrero de 1892, luego de la guerra civil que terminó con el suicidio del presidente José Manuel Balmaceda, Amunátegui Solar publicaba en El Heraldo de Santiago una defensa de la Biblioteca del Instituto y de su director (Mss. GRM 149). Afirmaba que "pocos literatos americanos hai que conozcan más a fondo la vida social y política de estas repúblicas y que fueran más capaces de narrarla con imparcialidad y elevación de miras". Como profesor, Moreno escribió un Manual de literatura preceptiva que en 1892 era comentado por E. M. Hostos en el periódico La libertad electoral como libro de "gran libertad y personalidad" (Mss. GRM 150). De su cátedra de literatura en el Instituto Nacional, Moreno dijo que era el mayor logro y promoción

${ }_{9}^{9}$ El asunto dio lugar a un folleto suyo contra el presidente boliviano: MORENO 1881. 
que había alcanzado en su vida. Con sus estudiantes leía y comentaba tragedias de Eurípides, La Vida es Sueño de Calderón, Los Persas de Esquilo, Hécuba de Eurípides y Atalia de Racine, entre otros clásicos (Mss. GRM 126).

\title{
Celibato, soledad y flirteos con la muerte
}

Su soledad íntima puede vislumbrarse en los recuerdos de Rosalía Calvo Cruchaga, hija de una familia santiaguina que lo acogió en su fundo, donde el bibliotecario pasaba temporadas de descanso. ${ }^{10}$ Recordaba Calvo que Moreno era retraído, mas "consecuente y leal con los que llamaba sus amigos", y que no era buen jinete, lo que indica que no era amigo de asociaciones masculinas gregarias. Les propuso matrimonio a Flora y a Lucía, hermanas de Rosalía, quienes lo rechazaron. En las veladas con la familia hablaba mucho sobre Santa Cruz, a la que se refería como "allá". Y "le causaba placer pisar las bellotas en los paseos", lo que sugiere el disfrute en solitario. A quienes lo conminaron a casarse o lo reconvinieron por su soltería, les contestó en el prólogo de su Biblioteca boliviana:

\begin{abstract}
"Algunas personas amigas han dado en la flor de preguntar al autor de este catálogo, ¿por qué no se casa?"... He acometido el presente inventario penetrado de una modestia infinita, llevándolo a cabo con heroica paciencia i en mitad de los más grandes conflictos... Irá a parar a manos de un centenar de coleccionistas i a las catacumbas de otras tantas bibliotecas. Irá también a poder de las treinta i cinco personas, según cuentas, que se han servido deplorar de algún tiempo a esta parte el no haberme visto casado i con hijos. Un respetable amigo de esta ciudad, diputado, gran aconsejador de que se casen, enjendrador mui prolífico (once lejítimos en 9 años), i que gasta mui mala ortografía, al hojear este catálogo, volviéndose hacia mí con una mirada terriblemente injenua, me preguntó: "¿I para qué sirve todo esto?". iAh! Mi catálogo no será, no, tan simple ni tan humilde que vaya a buscarle (MORENO 1879, p. V).
\end{abstract}

El coleccionista recibió un golpe grande con la noticia del incendio de su biblioteca en 1881, cuando se hallaba ausente de Chile y su biblioteca embalada en casa de su amigo el químico Daniel Vives. Según Luis Montt, quien se hizo cargo de la recuperación de las cajas afectadas, el daño en los libros fue mínimo, pero considerable en los manuscritos. Cuando aun no conocía la extensión del daño, y acaso juzgándola mayor, Moreno escribió a Vives las siguientes palabras reveladoras:

[...] aquello era el único jirón de patria, la sola familia, el último refugio. Representaba toda la herramienta y el material acumulado durante diez años para un trabajo que comenzaba cuando estalló la guerra. Según esto y en vista de lo salvado, ¿significa el desastre un perjuicio o una ruina? Porque en verdad, si equivaliese a esto último, el desastre con él y con lo que en la misma vía llevo padecido en otras partes, tengo ya lo suficiente para notificarme del desahucio... Apelo a un pleno conocimiento de causa antes de adoptar una solución definitiva (VARIOS AUTORES 1986, p.115). ${ }^{11}$

\footnotetext{
${ }_{10}$ Carta de Rosalía Calvo Cruchaga de Aldunate Valdés a Julio Salmón, Santiago, ene. 1932, publicada por VÁSQUEZ MACHICADO 1937.

${ }_{11}$ Carta de Gabriel René Moreno a Daniel R. Vives, Buenos Aires, 8 de febrero de 1882, compilación e introducción de José Luis Roca.
} 
El daño no fue catastrófico y el trabajo pudo seguir su curso. Luego, Moreno sufrió una recaída y decidió interrumpir Últimos días, lo que no le impidió publicar lo escrito y en 1901 un volumen de documentos. Tras su muerte, su hermano Aristides recibía en Iquique las 81 cajas embaladas que contenían su biblioteca, vendida al Estado boliviano (Mss. GRM 165).

\section{Moreno intempestivo: el historicismo americano acoge la ironía contemporánea}

Moreno escribió en Santiago de Chile, durante las últimas tres décadas del siglo XIX, sobre la Audiencia de Charcas de los últimos años coloniales. Es decir, desde una de las ciudades más modernas y pujantes de la América republicana, y sobre la esquina más mediterránea y "colonial" del Imperio Español. En Chile, sin voz ni voto, debió guardarse sus opiniones políticas, y en sus últimos años fue testigo del estéril parlamentarismo chileno y de los continuados estertores de Bolivia, regímenes cada vez más férreamente controlados por oligarquías clientes. Moreno se formó escéptico ante ficciones patrióticas y sobornos de la conciencia, rechazó las opiniones convencionales de las mayorías y poseyó el fuego secreto de la libertad.

Moreno publicó Últimos días dos años después de que saliera de las prensas de Rafael Jover, en Santiago, el décimo tercer volumen de la Historia jeneral de Chile, de Diego Barros Arana (que completaría sus 16 volúmenes en 1902, un año después de la publicación del volumen de documentos que Moreno 168 decidió agregar a su obra). Hacía décadas que la mayor parte de las historias monumentales de las repúblicas americanas había sido escritas, habían llegado a ser canónicas en la cultura escrita y habían dado lugar a historias temáticas $y$, en los últimos años, a trabajos de erudición bibliográfica, como los del mismo Moreno, los del mexicano Joaquín García Icazbalceta, de los venezolanos José Félix Blanco y Ramón Azpurúa, del chileno José Toribio Medina o del colombiano Eduardo Posada. Por entonces eran venerables historias de las revoluciones de independencia como las de Carlos María Bustamante en México, José Manuel Restrepo en Colombia o David Ramsay y Mercy Otis Warren en Estados Unidos. También lo eran las historias generales de Haití por Thomas Madiou, de Brasil por Francisco Adolpho Varnhagen, de Estados Unidos por George Bancroft o de Ecuador por Federico González Suárez.

En fin, surgían por entonces las rimas y sones de una nueva sensibilidad. En Chile, el hijo del presidente Balmaceda, Pedro, era anfitrión en la Moneda de Rubén Darío y seguidor convencido de la estética de Azul, que el nicaragüense había publicado en 1888. En Colombia, en 1896, año de publicación de Últimos días, se suicidaba José Asunción Silva dejando inédita su novela De Sobremesa, sin duda obra de catarsis en que el poeta imaginó la libertad moderna en la república. En Montevideo, Rodó publicaba su Ariel cuando Moreno preparaba el volumen de documentos que acompañó a Últimos días. En fin, no en vano Moreno era profesor de literatura en el Instituto Nacional, y autor de una "preceptiva" sobre la materia.

El oficio de Moreno fue el de historiador, su fuerte la erudición y su sensibilidad la del poeta. Vivió a plenitud la escritura histórica de su siglo y 
la llevó más lejos. En sus Últimos días coloniales en el Alto Perú entregó el relevo de la interpretación americana a los poetas modernistas. Les dio la irreverencia, la preferencia del amor a la verdad sobre el amor a la patria, la ironía y la experimentación con el lenguaje. En su libro, Moreno trascendió las convenciones de la historia tradicional, y antes de que las ciencias sociales maduraran su nueva guisa, trajo a la interpretación de las repúblicas americanas la actitud crítica de un librepensador y de un ciudadano moderno; la fuerza argumentativa de la erudición a toda prueba; y el lenguaje y la sensibilidad que ya sonaban en boca de los poetas parnasianos y modernistas. Pero este último es tema de otro estudio.

\section{Referencias bibliográficas}

ARNADE, Charles W. The Historiography of Colonial and Modern Bolivia. The Hispanic American Historical Review. Durham, Carolina del Norte, 1962. v. XLIII, n. 3, p. 333-384.

BARNADAS, Josep. Gabriel René Moreno (1836-1908): drama y gloria de un boliviano. La Paz: Ediciones Altiplano, 1988.

COLMENARES, Germán. Convenciones contra la cultura: ensayos sobre la Historiografía Hispanoamericana del siglo XIX. Bogotá: Tercer Mundo, 1987.

CONDARCO MORALES, Ramiro. Grandeza y soledad de Moreno: esbozo biobibliográfico del príncipe de las letras bolivianas. La Paz: Talleres Gráficos Bolivianos, 1971.

FINOT, Emilio. Gabriel René Moreno y sus obras: apuntes bio-bibliográficos. Santa Cruz de la Sierra: Tipografía Comercial, 1910.

MEDINACELLI, Carlos. Letras bolivianas. Kollasuyo. La Paz, 1946. Año VIII, n. 63 , p. $185-194$.

MEJÍA, Sergio. ¿Qué hacer con las historias latinoamericanas del siglo XIX? - En respuesta al historiador Germán Colmenares. Anuario Colombiano de Historia Social y de la Cultura. Bogotá, 2007. Universidad Nacional de Colombia. n. 34, p. 425-458.

. La noción de historicismo americano y el estudio de las culturas escritas americanas. Historia Crítica, Bogotá, nov. 2009. Universidad de los Andes. Edición especial, p. 246-260.

MENDOZA, Gunnar. Gabriel René Moreno, bibliógrafo boliviano. Revista de la Universidad de San Francisco Xavier. Sucre, 1951. t. XVI, n. 39-40, p. 553-613 (separata de la misma revista, 1954).

MENDOZA, Jaime. Dos entrevistas con Gabriel René Moreno. Revista de la Sociedad Geográfica "Sucre". Sucre, 26 feb. 1937, p. 100-108.

MORENO, Gabriel René. Biblioteca Boliviana: catálogo de la sección de Libros y Folletos. Santiago: Imprenta Gutemberg, 1879, 889 p. 
Biblioteca Boliviana: catálogo del Archivo de Mojos y Chiquitos. Santiago: Imprenta Gutemberg, 1888, 628 p.

Bolivia y Argentina: notas biográficas y bibliográficas. Santiago: Imprenta Cervantes, 1901, 553 p.

. Daza y las bases chilenas de 1879. Sucre: Tipografía de El Progreso, 1881. Folleto. 21 p. Se publicó un avance en EI Ferrocarril. Santiago, 27 feb. 1881. n. 7930.

. Ensayo sobre la Historia de Bolivia por Manuel José Cortés. Revista del Pacífico. Valparaíso, 1861. Tomo V, p. 219-231 y 385-401.

Estudios de Literatura Boliviana. Potosí: Editorial Potosí, 1955 / 1956, dos volúmenes editados por Humberto Vásquez Machicado.

últimos días coloniales en el Alto Perú - Documentos inéditos de 1808 y 1809. Santiago de Chile: Imprenta, litografía i encuadernación Barcelona, 1901, 352 p.

. Últimos días coloniales en el Alto Perú. Santiago de Chile: Imprenta Cervantes, 1896, $474 \mathrm{p}$.

OVANDO SANZ, Guillermo. Gabriel René-Moreno. La Paz: Fundación Humberto Vásquez Machicado, 1996.

PRÓLOGO. Anales de la prensa boliviana: matanzas de Yáñez, 1861-1862.

Santiago: Imprenta de Cervantes, 1886.

ROCA, José Luis Roca (ed.). Gabriel René Moreno íntimo, 1836-1908. La Paz: Don Bosco, 1986.

1809: La revolución de la Audiencia de Charcas en Chuquisaca y en La Paz. La Paz: Plural, 1998.

. G. René-Moreno, el hispanoamericano. La Paz: Editorial Don Bosco, 1988.

SANABRIA FERNÁNDEZ, Hernando. Gabriel René Moreno. Revista Interamericana de Bibliografía. Austin, Universidad de Texas, 1961, ene.-mar. Segunda época, v. XI, n. 1, p. 25-54.

SILES GUEVARA, Juan. Contribución a la bibliografía de Gabriel René Moreno. La Paz: Universidad de San Andrés, 1967.

. Gabriel René Moreno, historiador boliviano. La Paz: Los Amigos del Libro, 1979 (tesis de maestría en la Universidad de Texas, en Austin).

VARIOS AUTORES. Antología de ensayos sobre Últimos días coloniales en el Alto Perú. Sucre: Archivo y Biblioteca Nacionales de Bolivia, 1996.

VARIOS AUTORES. Estudios sobre Gabriel René Moreno: homenaje al sesquicentenario del nacimiento de Gabriel René Moreno. Santa Cruz de la Sierra: Casa de la Cultura "Raúl Otero Reiche", 1986.

WARDROPPER, Bruce W. Don Quixote: Story or History? Modern Philology. Agosto, 1965. Vol. 63, n. 1, p. 1-11. 
WHITE, Hayden. Metahistory: The Historical Imagination of NineteenthCentury Europe. Baltimore: 1973.

Documentos en el Archivo Nacional de Bolivia en Sucre

Mss. GRM 126. Cátedra de preceptiva en el Instituto Nacional de Santiago - Composiciones de los alumnos. Trabajos de sus estudiantes de literatura en el Instituto; 26 piezas.

Mss. GRM 146. Documentos varios sobre la vida pública de Moreno.

F.1: nombramiento de Moreno como bibliotecario interino del Instituto Nacional por decreto 571 del presidente de la república, comunicado al rector del Instituto, F. Errázuriz, en Santiago, 30 mar. 1868.

Mss. GRM 146. Documentos varios sobre la vida pública de Moreno. F.3: nombramiento de Moreno como profesor interino de la clase de Literatura en el Instituto Nacional por decreto 2204, comunicado al rector del Instituto, Domingo Amunátegui Solar, en Santiago, 6 jul. 1887.

Mss. GRM 149. Recorte de un artículo de periódico con firma de Domingo Amunátegui Solar, titulado La Biblioteca del Instituto Nacional. El Heraldo. Santiago, 17 feb. 1892.

Mss. GRM 150. Recorte de artículo titulado Literatura preceptiva de Gabriel René Moreno. La libertad electoral. Santiago, 1892. n. 1710, vol. 20.

Mss. GRM 165. Demostración del contenido, por volúmenes, de 81 cajas que contienen la Biblioteca BOLIVIANO-AMERICANA de G. René Moreno. Trece hojas mecanografiadas en tinta violeta, firmadas por Aristides Moreno en Iquique el 4 de mayo de 1909, en que se especifica el número de libros contenidos en cada una de las cajas. 